\title{
O Estado Imperial e os Pequenos Impérios
}

Fábio Faversani*

Resumo: O artigo analisa o conceito de Estado e as relações entre sociedade e Estado na obra de Sêneca.

Palavras-chave: Estado, Sociedade Romana, Sêneca.

No pensamento de Sêneca, o Imperador ocupa o ponto mais alto da hierarquia social e, portanto, é um importante elemento ordenador desta. Além disso, é apenas ele quem pode colocar ordem e dar coesão à imensa massa de pequenos impérios. Iremos discutir esse papel desempenhado pelo Imperador no que se refere ao ordenamento social e aos conflitos e solidariedades construídos entre os grupos sociais.

Antes de mais nada, cremos que seria útil fazer um pequeno exame de como a historiografia tem apresentado o Estado, especialmente sob o principado Romano. Cremos poder estabelecer, para fins de síntese, a existência de duas grandes tendências quando se trata de analisar o Estado. ${ }^{1}$

A primeira delas, mais antiga, é derivada da obra de Theodor Mommsen e tende a ver o Estado como o conjunto de seus aparatos institucionais. ${ }^{2}$ Ou seja, o Estado é assimilado ao aparelho de Estado. ${ }^{3}$ Nessa perspectiva, é fundamental ver como se distribui o poder entre o Imperador e o Senado, que parecem compor uma diarquia, e, de modo auxiliar, como outros aparatos institucionais mostram-se capazes de intervir nas decisões do Estado.

A segunda grande tendência, crítica com relação à primeira, indica que as instituições não respondiam por boa parte da formulação e implementação das políticas do Estado. Nessa perspectiva, o Estado seria um subproduto da sociedade, resultado das interações e jogos de pressão e contrapressão existentes no meio social. Os que se consolidam como homens de poder na sociedade ditam o funcionamento do Estado, sendo as instituições praticamente irrelevantes por si, valendo apenas para serem colocadas a serviço de um uso clientelístico desse aparato pelo governante e seus aliados. $^{4}$ 
Essa tendência hoje é hegemônica. Em Saller, por exemplo, os determinantes são os mecanismos de distribuição do poder pelo princeps a seus amigos de alto e baixo status e a atuação da familia Caesaris.

Um primeiro limite a essa perspectiva é o seu caráter tautológico. O que faz haver uma hierarquia entre os amigos do Imperador é sua maior ou menor proximidade com o governante. Como o que constrói essa posição é a relação em si, temos que, segundo essa proposição, alguém tem uma posição destacada porque ocupa uma situação de proximidade com o Imperador e o fato de ele gozar dessa situação deriva de ser um amigo próximo do Imperador. Ou seja, quem é próximo ao Imperador tem poder e tem poder quem é próximo ao Imperador. Ao explicar um fator pelo outro reciprocamente, tem-se uma não-explicação. Essa tautologia aparece com a eliminação do peso das instituições e normações legais que eram geridas pelo Estado, somada à substituição completa das estruturas formais de poder, que seriam meros pesos mortos, por uma rede clientelística que ocuparia o Estado. Um último ingrediente da construção da tautologia advém da pouca importância dada às diferenciações impostas para os agentes pelo mercado.

Wallace-Hadrill, ao adotar a noção de sociedade de corte, para um outro exemplo, tentou superar esse limite colocado pela falta de um aparato teórico que situe as relações clientelísticas a par de outros tipos de relação social que não desaparecem nem são substituídas pela clientela. Não nos parece que conseguiu. Em primeiro lugar, Norbert Elias, com esse conceito, procurava explicar um aspecto que the parecia importante em certas sociedades de Antigo Regime. ${ }^{5}$ Mas tratava-se de um aspecto apenas. Não havia ali a pretensão de dizer que a sociedade de corte era o Estado e muito menos a sociedade. Assim, parece-nos que a tentativa de Wallace-Hadrill não supera os problemas teóricos colocados pela perspectiva construída por diversos autores que têm se inspirado largamente nas contribuições de Moses Finley.

Em síntese, cremos que é possível afirmar que, para os primeiros, o Estado normatizaria e "faria” a sociedade, enquanto para os segundos é o contrário que ocorre, ou seja, a sociedade "faria” o Estado.

Essas determinações absolutas não nos parecem a melhor maneira de ver o Estado. Aliás, não será demais destacar que essa percepção predominantemente normativa (Mommsen) ou legitimada por cooptação (seguidores de Finley) não encontra guarida na literatura sociológica contemporânea. O Estado é normativo à medida que impõe e constrange os indivíduos a seguirem determinadas normas que não 
seguiriam a partir de seu exclusivo interesse pessoal. Outrossim, se o Estado fosse apenas uma instância de constrangimento dos indivíduos, que não veriam nele nenhuma utilidade para seus interesses (quer sejam egoisticamente orientados, quer sejam eles altruístas, não importa aqui), ele não teria como existir. É necessário que o Estado, além de normativo, conte com alguma legitimidade e, portanto, mecanismos de cooptação que façam com que essa normatização seja acatada em alguma medida. Sem isso, o Estado não tem como sustentar sua existência. ${ }^{6}$

Assim, parece-nos razoável partir de uma definição (que sintetiza um debate na literatura sociológica) para examinarmos o Estado em Sêneca. Segundo Anthony Giddens:

Todos os Estados, tradicionais ou modernos, abarcam algumas características gerais. Um Estado existe onde há um aparato político (instituições governamentais, tais como corte, parlamento ou congresso, além de pessoal do serviço civil), governando sobre um dado território, cuja autoridade é sustentada sobre um sistema legal e por sua capacidade de usar a força para implementar suas políticas. ${ }^{7}$

Esse conceito de Giddens nos parece claramente apontar que o Estado é, ao mesmo tempo, um organismo normativo, aparatos institucionais e uma instância sistêmica acatada em certa medida por aqueles que são governados, sem prescindir, contudo, de um aparato repressivo que constranja seus governados a acatar a autoridade daquelas normatizações. O Estado, tal como definido por Giddens, é o Estado de Mommsen e aquele dos seguidores de Finley ao mesmo tempo.

Dito isso, passemos a analisar o Estado que Sêneca nos apresenta.

Um dado claro na obra de Sêneca, em especial na leitura de Apocolocyntosis e De clementia, é a centralidade atribuída à figura do Imperador. Muitas vezes há uma assimilação entre governante e Estado.

Assim sendo, o Imperador deveria gerir um verdadeiro clientelismo de Estado do qual ele seria o centro. Os pequenos impérios estariam articulados por meio da atuação do imperador. Mas isso não significa que a articulação dos grupos coincidiria com o Império.

Para Sêneca, essa situação de grande articulação dos grupos em torno do Imperador derivava de um fato historicamente situado, não era algo natural e muito menos ideal. Esse fato decisivo é a morte do amor pela liberdade entre os romanos. Sêneca data essa transformação de qualidade com a morte de Catão. Uma das passagens em que ele apresenta o argumento é a seguinte: 
Ninguém de certo demonstrou mais coragem do que este homem [M. Catão] que se ergueu contra César e Pompeu, que desafiou por igual quer os cesarianos, quer os pompeianos, mostrando que havia um terceiro partido: o da República! [...] [Para ele], preferível seria ser feito escravo a força do que aceitar a escravidão sem resistência! [...] A questão não consistia em saber se Catão seria livre, mas sim se viveria entre homens livres. ${ }^{8}$ Catão [...], viva imagem de virtudes, que, lançando-se contra sua espada, fez ver a todos que findavam a um tempo ele e a república.

Essa transição entre um momento histórico em que o melhor seria a República (até Catão) e outro, em que a Monarquia é a opção mais razoável, fica clara quanto Sêneca apresenta o seguinte julgamento:

Costuma-se discutir se Marco Bruto deveria ter recebido a vida que o divino Júlio lhe dava depois de tê-lo julgado digno de morte. Em outra ocasião trataremos dos motivos que teve para matá-lo; porque para mim, tendo sido em todas as demais ações um grande homem, parece que nesta errou grandemente e que não se portou como um estóico; porque, ou temeu o nome de rei (que é o melhor estado para uma cidade, desde que sob o poder de um rei justo), ou julgou que poderia haver liberdade em um povo onde teria recompensa para o mandar e o obedecer, ou pensou que a cidade que tinha perdido seus antigos costumes poderia voltar à sua primeira forma, ou que havia igualdade no direito dos cidadãos, ou que as leis eram observadas por um povo onde milhares de homens brigavam não para saber se tinham que servir, mas para determinar a quem teriam que servir. Grande foi o silêncio que teve da natureza ou de sua cidade, pois acreditou que, morto um, faltariam outros que quisessem o mesmo. ${ }^{10}$

Essa passagem sintetiza uma série de elementos que vale a pena examinar. Em primeiro lugar, a liberdade acabou e, assim, não pode haver República. Resta então a possibilidade de se ter um monarca justo. É nessa alternativa que se deve investir. Ele destaca que há um ordenamento dado pelo fim da “igualdade no direito dos cidadãos” e na inobservância das "leis”. Ou seja, já aqui fica claro que o Estado tem um aparato institucional que se relaciona com a forma com que as pessoas se ordenam fora dele. Os dois aspectos se imbricam e devem ser levados em conta no pensamento de Sêneca.

Os homens de sua época escapavam à liberdade e à justiça. Ainda que a historiografia destaque muito a tirania dos Imperadores, Sêneca a via por toda parte. No geral, ele indica que: "ficas indignado quando teu escravo te responde, e seu liberto, esposa ou clientes: ao mesmo tempo reclama que foi suprimida do Estado aquela liberdade que baniste de ti”. ${ }^{11}$ Argumentava ele que são várias as coisas que nos ameaçam, “como um acusador indigno ou uma acusação falsa ou ódios de poderosos irados contra nós ou outras violências comuns entre os togados”. 12 Ainda mais,

o Senado, este conselho público, sem esperar as eleições, sem nomear um general, reúne os ministros de sua ira e perseguindo nobres jovens nas casas, ele próprio se faz executor de suplícios. $^{13}$

Ainda tratando do Senado, afirma que "quando o governo passa na sua maior parte pelo Senado, ${ }^{14}$ são seus homens que, a título pessoal, receberam do povo o poder 
que exercem contra o próprio povo”. Outro lugar institucional no pensamento de Sêneca, esse mais difuso, mas não menos importante, é o povo romano. Para Sêneca, é importante que haja alguém com poderes suficientes para pôr ordem a esses homens sempre dispostos à tirania. Daí a necessidade de um "rei justo” onde não se tem um povo justo. É o máximo que se pode esperar. Mas esse “rei justo" deve ser o exemplo que contamina os súditos, ou seja, precisa ser capaz de produzir alguma adesão ao seu governo, e, ao mesmo tempo, aquele que pune - e precisa contar com aparatos estatais para tal fim.

Quanto à institucionalidade do Estado, ela sempre é lembrada ao longo dos escritos de Sêneca. Vejamos alguns exemplos. Essa institucionalidade espalha-se por todas as partes do Império, ainda que a administração das províncias seja venal ${ }^{15}$ e a articulação com aliados seja baseada em favores espúrios e não em valores morais. ${ }^{16}$ É verdade que os textos de Sêneca pouco tratam desse aspecto provincial, concentrando sua atenção quase que exclusivamente em Roma.

Ou seja, mesmo sendo espaços institucionais venais, eles funcionam. Às vezes funcionam de tal maneira que garantem a estabilidade do Estado, apesar de este estar sendo dirigido por um mau governante. Esse é o caso que ele indica ter ocorrido sob Calígula, quando este se descuida do abastecimento da cidade de Roma, mas aqueles

a quem eram confiados os cuidados com o trigo público ..., com a maior dissimulação, encobriam um tal mal incrustado nas vísceras do Estado (o risco de desabastecimento) - e digo que o faziam com razão! Pois algumas doenças devem ser curadas sem que os pacientes as conheçam; a muitos, o conhecimento de sua doença foi a causa da morte. ${ }^{17}$

Há também os exércitos, ${ }^{18}$ importantes mesmo para o rei justo, pois o que diferencia esse do tirano não é ter armas a seu serviço, mas como as utiliza. Em De Clementia Sêneca diz textualmente: "nenhum dos dois (é) menos equipado em armas do que o outro”. ${ }^{19}$ Esses espaços institucionais são múltiplos e quase intermináveis. O seguinte trecho deixa claro como eles eram variados e vivos, mesmo que desprestigiados na conjuntura em que ele vivia:

Se a fortuna prevalecer e lhe tolher a faculdade de agir, que ele não fuja imediatamente, voltando-se desarmado e buscando abrigos - como se algum local houvesse em que a fortuna não poderia persegui-lo - , mas que ele então mais reservadamente se deixe levar às atividades e com critério encontre algo em que seja útil à cidade. A carreira militar não é permitida? Que ele procure as magistraturas. Deve-se reduzir à vida privada? Que ele seja orador. O silêncio é indicado? Que ele, calado, ajude os cidadãos. Perigoso ainda é o acesso ao foro? Nas casas, nos espetáculos, nos banquetes, que ele persiga o bom companheiro, o fiel e moderado amigo. Perdeu os deveres de cidadão? Que exerça os de homem. ${ }^{20}$ 
Cremos que essa passagem baste para mostrar que, por mais que Sêneca visse o Imperador como o detentor de poderes extraordinários, havia uma institucionalidade do Estado esvaziada por conta da incapacidade de seus contemporâneos a colocarem funcionando a contento, isto é, a serviço da justiça e da liberdade, segundo seus critérios. ${ }^{21}$ Procuravam, no mais das vezes, aproveitar-se do Estado para benefício próprio ou estavam totalmente desinteressados de suas obrigações. Mas o fato é que se aproveitavam do Estado ocupando espaços institucionais e agiam com incúria ao se descuidar de tarefas que lhe caberiam conforme os cargos que ocupassem.

O mesmo podia acontecer com o próprio Imperador, como no caso de Cláudio, por exemplo, que “costumava vender pequenos direitos de cidade” ${ }^{22}$ e ocupava seu governo a se distrair jogando dados. ${ }^{23}$

Nesse universo tão corrompido, a esperança de Sêneca era que surgisse um rei justo. Caberia a esse monarca estabelecer a ordem, ou seja, que a institucionalidade do Estado operasse exclusivamente a partir do exemplo do Imperador e que as posições dos indivíduos fossem asseguradas. Visto assim o primeiro aspecto que tínhamos destacado na passagem na qual Sêneca expõe seu ponto de vista sobre a ação homicida de Bruto, ou seja, a existência de uma institucionalidade do Estado, passemos ao segundo, qual seja, como essa ordem instituída tem importância para o ordenamento da sociedade.

Mas, antes, um parêntese. Muitas interpretações da obra de Sêneca, em especial do De Clementia, tendem a apontar para uma extrema centralização do Estado sob Nero. É uma interpretação curiosa. Sêneca afirma nessa obra que, em sua avaliação, deveria haver essa centralização sob Nero. Ou seja, ele não afirma que o Estado era centralizado, mas sim que deveria ser - é um sonho, um projeto - e, mais, isso seria válido apenas sob Nero ou outro sábio. Portanto, Sêneca não afirma que o Estado era centralizado e que Nero era plenipotenciário. Avalia que isso seria algo muito bom para todos que se obrigariam a seguir e imitar o exemplo de um rei justo, Nero!

Voltando à ordenação da sociedade. A ordenação da sociedade é fundada em restrições à liberdade. Segundo Sêneca, "nascemos em uma monarquia: liberdade é obedecer a deus”. ${ }^{24}$ Era fundamental prestar obediência à ordem - e a ordem, naquela conjuntura, era personalizada em última instância pelo Imperador - para que houvesse a preservação dessa mesma ordem e, portanto, dos direitos que ela pressupunha. Ainda que esses direitos fossem limitados, eram bem mais do que viver na desordem. De acordo com Sêneca, “essa cidade terá deixado de dominar no mesmo momento em que 
tiver deixado de prestar obediência”. ${ }^{25}$ Assim sendo, o Imperador "é o vínculo, cujo poder intervém na coesão das forças públicas. ... 'preservado o rei, todos têm um único ideal. Perdido o rei, todos rompem o compromisso de fidelidade"”. ${ }^{26}$ "Eis porque príncipes ou reis, ou qualquer nome que tenham, são os tutores da ordem pública." ${ }^{27}$

Ou seja, o Estado só existe onde há uma ordem pública, garantias e privilégios sociais que são aferidos e preservados pela existência do Estado. E não é possível pensar que Sêneca via este fator como o principal papel do Estado apenas quando escrevia o De Clementia. Essa perspectiva é mostrada de forma mais clara posteriormente, e está nas Epistulae Morales:

Quando o rei está incólume um só espírito reina, mas, morto ele, rompem-se os laços sociais!” O nosso rei é a alma; se esta permanece incólume, todas as nossas funções e deveres se realizam na mais perfeita ordem, mas se ela começa a oscilar, por pouco que seja, tudo o mais em nós é afetado. $^{28}$

Sem um ordenamento, nada perdura na sociedade. ${ }^{29}$ Assim, não há nada pior que a desordem.

Na desordem, ninguém tem acesso a nada que possa ser garantido pelo Estado; sob a Monarquia, conforme o gosto da Fortuna, todos podem ter. É assim que Sêneca, ainda sob Cláudio, diz que "mesmo ao próprio César, a quem tudo é lícito, por este motivo muitas coisas não são permitidas: a sua vigília protege o sono de todos, a sua fadiga, o ócio de todos; a sua atividade, os prazeres, o seu trabalho, o repouso". ${ }^{30} \mathrm{E}$ claro que Sêneca não estava completamente alheio à razão para imaginar que, sob Cláudio, todos vivessem dormindo tranqüilos, no ócio, em meio a prazeres e repousos. Ele aponta que essas possibilidades existem na sociedade não simplesmente porque os indivíduos as detêm, mas porque há um Estado que propicia esses espaços que são ocupados por alguns. ${ }^{31}$

Por isso, a nosso ver, a melhor passagem a ilustrar essa perspectiva é a seguinte:

laboram em erro aqueles que pensam ser os fiéis praticantes da filosofia homens insolentes e obstinados, que apenas sentem desprezo em relação aos magistrados, aos reis, a todos enfim a quem cabe o encargo da administração pública. É precisamente o contrário que se passa: nenhuma classe de pessoas lhes tem maior gratidão com toda a justiça, pois a ninguém seus préstimos são mais notórios que aos filósofos, aos quais proporcionam as benesses de uma vida de ócio e tranqüilidade. ${ }^{32}$ 
Assim, cremos poder concluir que Sêneca vê no Imperador o elemento que conjunturalmente personaliza o Estado em última instância, mas não é o Estado de fato. Outrossim, os grupos procuram extrair vantagens do Estado, mas eles em conjunto não são o Estado, ainda que procurem ocupá-lo a ponto de ameaçar a própria existência dos ganhos que dele expropriam. Assim, para Sêneca, o Estado é a ordenação que a sociedade deveria cumprir, incluídos os lugares sociais que esse ordenamento pressupõe, e o conjunto dos instrumentos existentes para coagir os indivíduos a se adequarem a ela.

\section{CONCLUSÕES}

1. O Estado não é o governante nem o conjunto dos que têm poder fora do Estado e que mandariam no governo. Esse entedimento redutor do Estado elimina o papel das lutas que podem levar a transormações no que se refere ao seu funcionamento e afasta dessas lutas todos os setores que são convencidos de que o Estado é algo alheio a si. Trata-se, portanto, de uma abordagem conservadora, de viés elitista. Avalio que é de abordagens desse matiz que se nutrem certas críticas que são feitas contemporaneamente ao Estado pela responsabilização exclusiva de seu governante, levando a população a crer que mudar o governante poderia levar a mudanças significativas no Estado por si só.

2. Não defendemos a idéia de que a predominância de solidariedades verticais, ou seja, entre desiguais, seja o mesmo que o fim dos conflitos e a implantação de uma ordem unipolar sob controle do Imperador ou, mais precisamente, da Casa Imperial. Há uma série de conflitos que permanencem no interior de cada um dos gupos e especialmente entre os grupos. Ademais, a predominância de solidariedades verticais não exclui a existência de quadros de solidariedade horizontal - entre «iguais» - nem que tal predominância seja algo «natural», própria a qualquer sociedade, atemporalmente. Do mesmo modo, essa predominância não se deve a uma cega admiração aos superiores hierárquicos, e muito menos por adesão cega a estes. Trata-se do resultado de um quadro específico de interesses, de construção de solidariedades e circuitos de comunicação específicos que leva a isso. ${ }^{33}$

FAVERSANI, Fábio. The Imperial State and the minor Empires. História, São Paulo, v. 26, n. 1, p 53-62, 2007. 
Abstract: This article aims at analyzing the concept of State and the relationships between society and State in Seneca's work.

Keywords: State, Roman Society, Seneca.

Artigo recebido em 04/2007. Aprovado em 06/2007.

\section{NOTAS:}

\footnotetext{
* Professor de História Antiga - Departamento de História - Instituto de Ciências Humanas e Sociais UFOP - 35420000 - Mariana/MG. E-mail: faversan@ichs.ufop.br

1 Não consideramos aqui o que poderia ser apontado como uma terceira grande tendência, por ser adotada por um número significativo de historiadores, notadamente quando se dedicam a produzir manuais de história romana. Trata-se de uma tendência a assimilar o Estado à figura do governante. Essa perspectiva assume diversos matizes, desde a apreciação da história romana lato sensu (e não só a do Estado) por reinados, associando a história de Roma à ação dos governantes e às reações que enfrentam; até aqueles que a apresentam como a forma como o Estado foi sendo transformado pela ação do governante. Essa perspectiva de apresentar a história romana através de uma história centrada em seus governantes é bastante usual por se adequar bem às fontes, em especial a Tácito, Dion Cássio e Suetônio, que organizam seus escritos históricos dessa maneira, basicamente. Além disso, no que se refere ao Estado, em particular, refletem a adoção de uma perspectiva de análise que renuncia a uma percepção fundada em uma elaboração teórica que supere os limites analíticos colocados pela apreensão que os contemporâneos construíram de seu tempo. Temos visto que Sêneca não conseguia notar articulações sistêmicas de certos fenômenos (como o imperialismo ou o escravismo). O mesmo ocorre para o Estado e para o mercado. Muitas vezes, os historiadores parecem ver o Estado mais ou menos como Sêneca, que dizia para Nero: "és a alma do Estado e o Estado é teu corpo" (De Clementia I, 5, 1).

2 Cf. STERNBERGER, Dolf. Dominación y Acuerdo. Barcelona: Editorial Gedisa, 1992. p.61.

3 Aproximando-se mais do desenho dos Estados Modernos, cf. NICOLET, Claude. Rendre à César: économie et société dans la Rome antique. Paris: Gallimard, 1988. p.277.

4 Uma perspectiva marxista tradicional de análise, hoje muito pouco em voga na historiografia da Antigüidade, poderia ser vista como um tipo distinto, porém aparentado desse segundo. No caso, o Estado aparece como epifenômeno não da sociedade simplesmente, mas das desigualdades de classe aí existentes. Mas, em razão de tal perspectiva de análise não ser adotada amplamente, preferimos deixá-la aqui, em nota de rodapé.

5 E não em todas, como ele já destaca na introdução.

6 Cremos que tal binômio controle da liberdade individual e promoção do interesse coletivo como uma função do Estado que pressupõe repressão e cooptação deriva de uma tradição já bastante assentada desde o iusnaturalismo, em especial a partir do debate colocado pelas obras de Rousseau e Hobbes.

7 GIDDENS, Anthony. Sociology. 2nd ed. Cambridge: Polity Press, 1994. p.309.

8 Epistulae Morales. XCV, 70-71. A mesma idéia (com Catão morre a liberdade) está em outras passagens: De Constantia Sapientis II, 3-4. Epistulae Morales CIV, 30-32, por exemplo.

9 De Tranquillitate Animi XVI, 1.

10 De Beneficiis II, XX, 1-2.

11 De Ira. III, XXXV, 1. O Senado também aparece como fonte de injustiças em Epistulae Morales $\mathrm{XIV}, 7$, entre outras passagens.

12 De Constantia Sapientis IX, 2. O grifo é nosso.

13 De Ira III, II, 4.

14 O que não acontecia naquele momento aos olhos de Sêneca, é verdade.

15 De Beneficiis I, IX, 5.

16 De Ira II, XXXIV, 4-5.

17 De Breuitate Vuitae XVII, 6.
} 
18 Lembrados também em sua capacidade de instabilizar a posição do governante no Estado: De Ira III XXX, 4-5; III, XXXI, 1. entre outras passagens.

$19 \mathrm{X}, 1$ e $3-5$

20 De Tranquillitate Animi IV, 2-3.

21 Além de uma outra série de espaços institucionais que Sêneca não menciona, mas que sabemos que existia, como os aparatos dedicados à cunhagem de moedas e tantos outros necessários a um Estado do porte daquele que foi o romano no século I d.C.

22 Apocolocyntosis IX, 4.

23 Apocolocyntosis XV,3

24 De Vita Beata XV, 7.

25 De Clementia III, II, 2.

26 Idem III, II, 1.

27 Idem III, II, 3.

28 Epistulae Morales CXIV, 23.

29 É nesse sentido que Sêneca lembra a afirmação de Demaratos, dirigida a Xerxes, tratando do seu exército: “não duraria muito o que não podia ser conduzido” (De Beneficiis VI, XXXI, 4).

30 Ad Polybium de Consolatione. VII, 2.

31 Essa garantia de espaço a alguns não se refere a pessoas particulares, mas à existência de lugares sociais que serão ocupados por diferentes indivíduos ao longo do tempo ao gosto da Fortuna. O que se pressupõe é a preservação de garantias e privilégios individuais e não indivíduos específicos.

32 Epistulae Morales LXXIII, 1. O grifo é nosso.

33 Para mais detalhes, cf. FAVERSANI, Fábio. A sociedade em Sêneca. São Paulo, 2001. Tese de doutorado em História Econômica - FFLCH-USP. 